This item was submitted to Loughborough's Research Repository by the author.

Items in Figshare are protected by copyright, with all rights reserved, unless otherwise indicated.

\title{
Exercise and ghrelin. A narrative overview of research
}

PLEASE CITE THE PUBLISHED VERSION

http://dx.doi.org/10.1016/j.appet.2013.04.018

PUBLISHER

(c) Elsevier

VERSION

AM (Accepted Manuscript)

LICENCE

CC BY-NC-ND 4.0

REPOSITORY RECORD

King, James A., Lucy K. Wasse, Myra A. Nimmo, and David J. Stensel. 2019. "Exercise and Ghrelin. A Narrative Overview of Research". figshare. https://hdl.handle.net/2134/12938. 
This item was submitted to Loughborough's Institutional Repository (https://dspace.lboro.ac.uk/) by the author and is made available under the following Creative Commons Licence conditions.

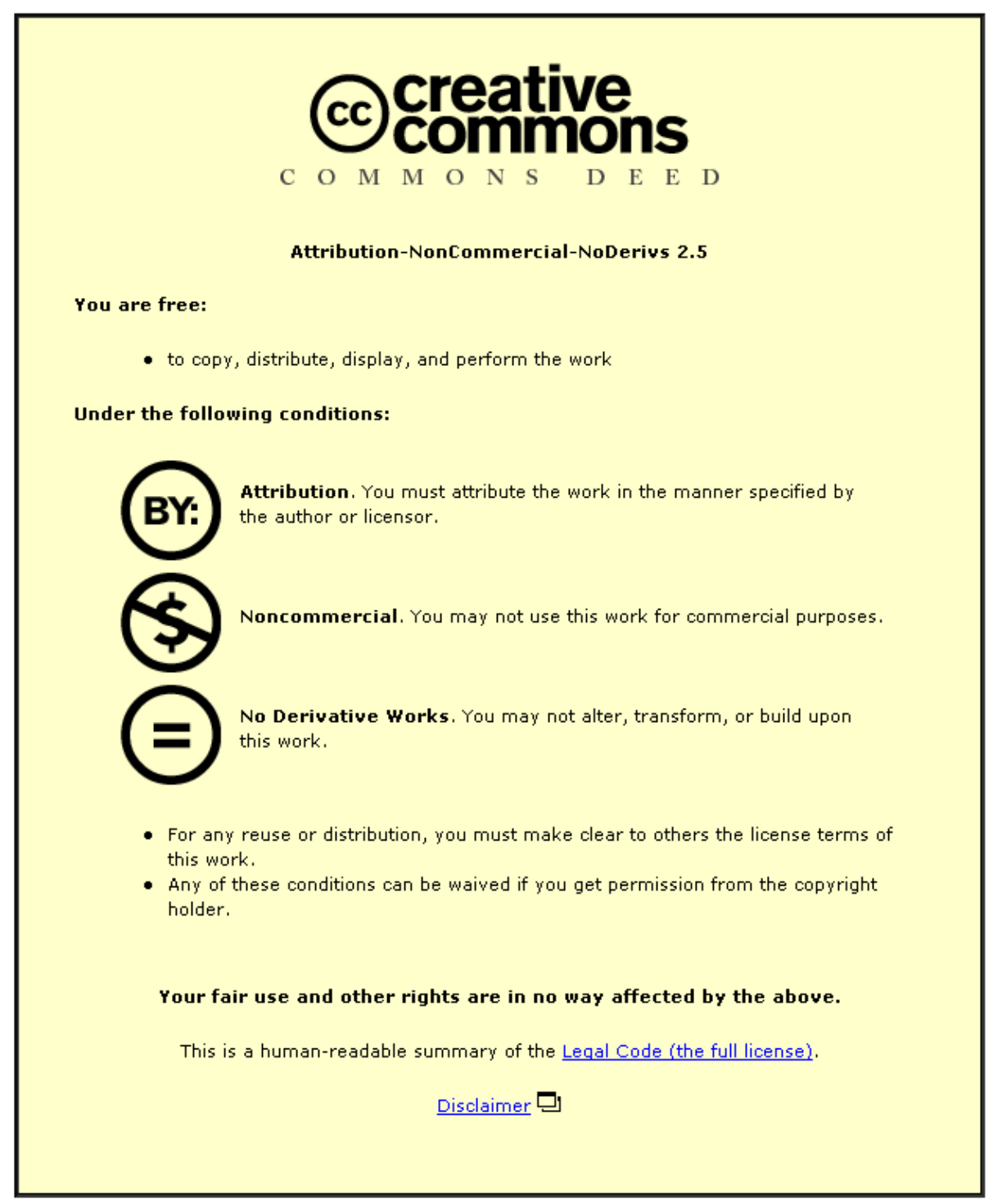

For the full text of this licence, please go to: http://creativecommons.org/licenses/by-nc-nd/2.5/ 


\section{Exercise and Ghrelin - A Narrative Overview of Research}

2 James A King ${ }^{1}$, Lucy K Wasse ${ }^{2}$, David J Stensel ${ }^{1}$, Myra A Nimmo ${ }^{1}$

$3{ }^{1}$ School of Sport, Exercise and Health Sciences, Loughborough University, UK, LE11

\section{$43 \mathrm{TU}$}

52 Institute of Inflammation and Repair - University of Manchester, UK, M13 9PL

6

\section{Correspondence}

$8 \quad$ Dr James King

9 School of Sport, Exercise and Health Sciences

10 Loughborough University

11 Leicestershire

12 LE11 3TU

13 UK

14 Phone: +44(0)1509 226324

$15 \quad$ Fax: $\quad+44(0) 1509226301$

16 E-mail: J.A.King@lboro.ac.uk

17

Disclosures - None

\section{Manuscript length - 6011 words}




\section{Abstract}

27 Since its discovery in 1999, ghrelin has been implicated in a multiplicity of physiological activities. Most notably, ghrelin has an important influence on energy metabolism and after the identification of its potent appetite stimulating effects ghrelin has been termed the 'hunger hormone.' Exercise is a stimulus which has a significant impact on energy homeostasis and consequently a substantial body of research has investigated the interaction between exercise and ghrelin. This narrative review provides an overview of research relating to the acute and chronic effects of exercise on circulating ghrelin (acylated, unacylated and total). To enhance study comparability, the scope of this review is limited to research undertaken in adult humans and consequently studies involving children and animals are not discussed. Although there is significant ambiguity within much of the early research, our review suggests that acute exercise transiently interferes with the production of acylated ghrelin. Furthermore, the consensus of evidence indicates that exercise training does not influence circulating ghrelin independent of weight loss. Additional research is needed to verify and extend the available literature, particularly by uncovering the mechanisms governing acute exercise-related changes and characterising responses in other populations such as females, older adults, and the obese.

\section{Key Words}

46 Ghrelin, Acylated Ghrelin, Exercise, Training, Appetite, Food Intake, Energy Balance 
Introduction

52

After an arduous search, in 1999 Kojima and colleagues reported the purification and identification of an endogenous ligand able to bind to the orphan growth hormone secretagogue receptor (GHSR-1a) and stimulate growth hormone (GH) secretion via a novel independent pathway (Kojima, 2008; Kojima et al., 1999). The researchers termed this peptide 'ghrelin' as a tribute to its potent GH-RELeasing action (Kojima, Hosoda, Matsuo, \& Kangawa, 2001). Unbeknown at the time, the importance of ghrelin in metabolism would turn out to be much more wide ranging than initially recognised.

Ghrelin is a 28 amino acid peptide produced primarily from $\mathrm{P} / \mathrm{D}_{1}$ cells in the stomach fundus, with much lesser amounts being synthesised in the intestine, pancreas and other peripheral organs including the testis, heart, adipose tissue and skin (Gutierrez et al., 2008; Stengel \& Tache, 2012). Upon fasting, and/or low circulating levels of glucose and insulin, ghrelin is secreted into the circulation where it is present in two forms, acylated and unacylated ( 1:4 ratio) (Stengel, Goebel, Wang, \& Taché, 2010). Acylated ghrelin is made explicit by the post-translational addition of a medium chain fatty acid, typically octanoate or decanoate, to its third amino acid residue (serine), a modification catalysed by ghrelin O acyltransferase (GOAT) (Gutierrez et al, 2008; Yang, Brown, Liang, \& Grishin, 2008) and which is essential for ghrelin to bind to the GHSR-1a to exert its primary hormonal and metabolic actions (Kojima \& Kangawa, 2005) (Figure 1).

\section{Insert figure 1 near here}

The biological activities of ghrelin are multifaceted which is consistent with the widespread distribution of its receptor in the brain e.g. hypothalamus, (Schellekens, 
Dinan \& Cryan, 2010) and peripheral tissues e.g. vagal afferents, adipose tissue, spleen, myocardium, thyroid, adrenal gland (Stengel \& Taché, 2012). In addition to its well defined role as a regulator of GH secretion, ghrelin is also understood to harbour complex roles in glucose metabolism (Delhanty \& van der Lely, 2011), gastrointestinal (Tack et al., 2006; Levin et al., 2006), reproductive (Muccioli et al., 2011), immune (Taub, 2008) and cardiovascular (Nagaya et al., 2001; Vlasova, Järvinen, \& Herzig, 2009) function. Unquestionably however, the most notable discovery has been the identification of ghrelin's central role in appetite regulation and energy homeostasis whereby ghrelin remains the only known circulating peptide which stimulates appetite and feeding. Research surrounding this unique characteristic of ghrelin has captured significant attention.

There is an extensive body of literature demonstrating that ghrelin administration augments food intake and over time leads to gains in body weight/adiposity (Asakawa et al., 2003; Nakazato et al., 2001; Shintani et al., 2001; Wren et al., 2000; Wren et al., 2001a). In humans, the appetite stimulating properties of ghrelin were first identified when hunger was reported as a side effect during an investigation examining the influence of ghrelin administration on GH dynamics (Arvat et al., 2001). Thereafter, in a landmark study, Wren and co-workers (2001b) published findings demonstrating a striking increase in hunger perceptions and ad libitum energy intake in response to intravenous ghrelin infusion. These results have subsequently been confirmed by other investigators in both lean and obese individuals (Druce et al, 2005; 2006). The diurnal circulating profile of ghrelin is also consistent with the notion that ghrelin influences appetite and feeding with circulating levels peaking before meal times and falling thereafter in proportion to the amount of ingested energy (Callaghan et al., 2004; 
101 Cummings et al., 2001). Ghrelin has subsequently been labelled the 'hunger hormone' 102 (Higgins, Gueorguiev, \& Korbonits, 2007).

The impact of ghrelin on energy metabolism extends beyond appetite regulation. Specifically, ghrelin promotes weight gain and adiposity by reducing energy expenditure (Pfluger et al., 2008) and fat oxidation (increases the respiratory exchange ratio) (Wortley et al., 2004), whilst promoting fat storage and the motivation to seek out energy dense food (Shimbara et al., 2004). In humans, circulating concentrations of ghrelin are inversely associated with body mass index and multiple measures of adiposity (Shiiya et al., 2002). Ghrelin levels are reduced in obese individuals

111 (Cummings et al., 2002; Tschöp et al., 2001; Vendrall et al., 2004) which may at least partly be mediated by impaired insulin sensitivity/hyperinsulinemia (McLaughlin, Abbasi, Lamendola, Frayo, \& Cumming, 2004). Augmented ghrelin therefore does not appear to be a mechanism which perpetuates obesity. Conversely, an attenuated postprandial suppression of ghrelin has been reported in obese individuals requiring a higher energy ingestion before a post-meal suppression is observed (English, Ghatei,

117 Malik, Bloom, \& Wilding, 2002; Le Roux et al., 2005). This may contribute to impaired satiety signalling in obesity and the propagation of positive energy balance.

In addition to its role in mediating the homeostatic control of energy balance, recent research has identified a role of ghrelin in the hedonic component of eating behaviour with studies showing that ghrelin increases the preference for foods with high palatability or high fat content (Egecioglu et al., 2010; Perello et al., 2009). This effect appears to be mediated by the activation of key brain regions associated with pleasure 
and reward (amygdala, orbitofrontal cortex, anterior insula and striatum) (Malik,

McGlone, Bedrossian, \& Dagher, 2008).

127

With the recognition of the apparent centrality of ghrelin in the control of appetite and energy metabolism it was not long before interest developed concerning the impact of exercise on ghrelin. Exercise influences diverse aspects of energy homeostasis and metabolism including appetite, energy expenditure, substrate utilisation or partitioning, body weight and composition. A decade ago the first studies investigating the impact of exercise on ghrelin appeared in the literature (Dall et al., 2002; Kallio et al., 2001) and since this time there has been an explosion of research within the area. This review aims to provide a narrative overview of studies that have examined both the acute and chronic impact of exercise on circulating levels of ghrelin in adult humans. At this point 
will segregate our discussion accordingly. In our text we will use the term 'ghrelin' to refer to total ghrelin. Conversely, we will specifically allude to acylated and unacylated ghrelin when talking about the individual ghrelin moieties. The intention of this review is not to provide a systematic or exhaustive account of studies in this area; rather we aim to identify and evaluate the most relevant studies with the objective of clarifying the development and status of research in this burgeoning area and to identify future important avenues of investigation.

\section{Acute exercise}

Ghrelin (total)

Initial interest regarding the acute effect of exercise on ghrelin emanated from a hypothesised role of ghrelin as a mediator of exercise-induced changes in GH. Circulating levels of GH rise markedly in response to moderate-high intensity exercise (Godfrey, Madgwick, \& Whyte, 2003) and after the discovery of ghrelin’s potent GH releasing action it was thought that ghrelin may orchestrate the exercise-related GH response. However, several early investigations did not observe any changes in circulating levels of ghrelin in response to moderate-high intensity bouts of running (Kraemer et al., 2004a; Schmidt, Maier, Schaller, 2004) or cycling (Dall et al., 2002; Kallio et al., 2001). This was despite notable increases in circulating levels of GH. These findings therefore demonstrate that changes in circulating levels of ghrelin do not mediate $\mathrm{GH}$ responses to exercise.

In subsequent years there was a second wave of interest about the interaction between exercise and ghrelin which was triggered by the identification of ghrelin as a critical regulator of appetite and energy homeostasis (Druce et al., 2005; Wren et al., 2001b). 
175 After the cementation of this discovery researchers were keen to investigate how exercise modulates this important appetite regulatory peptide. Questions arose as to whether ghrelin may in part mediate acute appetite changes with exercise e.g. 'exercise induced anorexia' (King et al., 1994), or whether circulating levels of ghrelin would change in response to deviations in energy balance. Unfortunately several initial studies examining the short-term influence of exercise on ghrelin were unable to establish a consensus (Christ et al., 2006; Dall et al., 2002; Erdmann, Tahbaz, Lippl, \& Wagenpfeil, 2007; Kallio et al., 2001; Kraemer et al., 2004a; Schmidt et al., 2004). However, these early studies were highly diverse in terms of the study designs which make it difficult to compare outcomes. Furthermore, many of these studies harboured significant methodological limitations relating to standardisation of pre-experimental diet and sample collection/assay procedure. Additionally, most of these studies did not implement a non-exercise control group making it impossible to determine whether outcomes were solely related to exercise.

In 2007 two studies with robust methodologies investigated acute changes in circulating levels of ghrelin during and for up to $1 \mathrm{~h}$ after moderate-high intensity exercise. Burns, Broom, Miyashita, Mundy, \& Stensel (2007) examined ghrelin responses to 60 min of moderate-high intensity running $\left(74 \% \dot{\mathrm{VO}}_{2}\right.$ max) in 18 young, healthy, men and women.

Despite hunger being suppressed during and for up to $1 \mathrm{~h}$ after exercise, ghrelin levels maximum heart rate) in 12 healthy men and women and observed no impact of exercise on ghrelin. It is possible in this study however that consumption of a small meal one 
hour before exercise may have lowered ghrelin concentrations and masked any effect of exercise.

The effects of rowing on circulating ghrelin has been the subject of intense investigation by one particular European research group working with elite athletes (Jürämie et al, 2007a; Jürämie, Jürämie, Purge, 2007b; Jürämie et al., 2009). In their first publication the researchers examined the ghrelin response to $30 \mathrm{~min}$ of sculling at $\sim 79 \%$ of maximum oxygen consumption. Immediately after exercise circulating ghrelin levels were $\sim 7 \%$ higher although this was not quite statistically significant. In a subsequent study these researchers reported a significant increase in ghrelin (24\%) immediately after exercise in response to a maximal rowing ergometer test (average duration $\sim 20$ min, intensity $81 \% \dot{\mathrm{VO}_{2}}$ max). This effect was transient however as no differences were apparent 30 min after the end of exercise. Each of these two studies lacked control groups however making it impossible to determine whether changes in ghrelin were solely related to exercise. To address this, in a third investigation these researchers assessed ghrelin responses to a 2 h rowing training session ( $\sim 67 \%$ heart rate max) with participants also completing a non-exercise control trial. The authors reported that exercise significantly increased (15\%) ghrelin when measured 30 min after exercise, but not immediately after. The findings from these investigations contradict those of Burns et al (2007) and Martins et al (2007) and the reason for this is not clear. It is possible that these discrepancies are due to factors related to the differing modes of exercise, however it is perhaps more likely that differences in dietary control, sample collection/processing and assay procedure are implicated (Chandarana et al., 2009). 
223 A handful of studies implementing both aerobic (Malkova, McLaughlin, Manthou,

224 Wallace, \& Nimmo, 2008; Toshinai et al, 2007; Vestergaard et al, 2007) and resistance

225

226 exercise (Ballard et al., 2009; Ghanbari-Niaki, 2006; Kraemer et al., 2004b) have reported decreases in circulating ghrelin in response to single bouts of exercise. Notably, Toshinai et al (2007) examined ghrelin responses to 40 min of graded intensity cycling (four, 10 min stages progressing from light to high intensity) in five healthy males. Plasma ghrelin was suppressed in an intensity dependent fashion. Furthermore, changes in ghrelin were associated with changes in plasma adrenaline $(r=-0.533)$ and noradrenaline ( $r=-0.603)$, an outcome which the authors suggested may indicate a causal mechanism, namely, a sympathetically mediated reduction in gastric blood flow causing decreased delivery of ghrelin into the circulation. An inhibitory effect of GH has also been posited as a mechanism responsible for suppressed ghrelin levels in response to exercise. Specifically, Vestergaard et al (2007) examined the independent and additive effects of GH therapy and acute exercise on post-exercise ghrelin responses. Exercise and GH therapy additively suppressed post-exercise ghrelin concentrations in the circulation with the exercise response being inversely associated with changes in $\mathrm{GH}(r=-0.35)$.

\section{Acylated ghrelin}

The appetite stimulating function of ghrelin is now understood to be chiefly determined by acylated ghrelin, via signalling through the GHSR-1a (Kojima et al., 1999). Within appetite related research, emphasis has subsequently shifted to acylated ghrelin, and the relatively recent development of assays specific for acylated and unacylated ghrelin has enabled this change in focus (Hosoda et al, 2004). Accordingly, recent research has unveiled notable differences in the responses of the individual ghrelin moieties to 
various stimuli including nutrition and energy balance (Liu et al., 2008). Thus, it was not long before researchers became interested in the specific interaction between acylated ghrelin and exercise.

251

Broom, Stensel, Bishop, Burns, \& Miyashita (2007) were the first to publish data regarding the acute effects of exercise on circulating acylated ghrelin. In their investigation nine healthy males completed an exercise trial and a control trial in a randomised crossover fashion. After an overnight fast, participants completed 60 min of treadmill running at $72 \%$ of $\dot{\mathrm{V}} \mathrm{O}_{2}$ max and then rested for eight hours. Plasma acylated ghrelin was significantly lower during exercise and immediately after. Moreover, subjective ratings of hunger were significantly reduced over the first three hours of the appetite suppression that occurs in response to moderate-high intensity exercise. resistance exercise (Broom et al., 2009; Deighton, Barry, Connon, \& Stensel, 2012;

271 King, Wasse, \& Stensel, 2011b; Wasse, Sunderland, King, Miyashita, \& Stensel, 2013). 
273 intensity exercise such as walking or cycling (45-50\% of $\dot{\mathrm{VO}}_{2}$ max) does not affect

274 circulating acylated ghrelin (King et al, 2010b: Ueda et al, 2009). Broom \& Stensel

275 (2006) specifically examined this issue and demonstrated that whilst treadmill running at $75 \%$ of $\dot{\mathrm{VO}_{2}}$ max markedly suppressed acylated ghrelin, running at $50 \%$ of $\dot{\mathrm{V}}{ }_{2}$ max had no effect. This mediating influence of intensity may point to possible regulatory mechanisms governing this response, with intensity dependent reductions in splanchnic blood flow and/or augmented sympathetic output at higher exercise intensities potentially interfering with ghrelin production or acylation (Burns et al., 2007; Toshinai et al., 2007). Circulating levels of insulin and glucose are key mediators of prandial ghrelin responses however neither likely affect exercise responses given that circulating insulin concentrations are suppressed during exercise (intensity dependent) (Galbo,

Christensen \& Holst, 1977) whilst glucose levels remain stable or decrease with prolonged exercise without exogenous carbohydrate (Wagenmakers et al., 1991).

One of the limitations of many studies which have examined gut hormone responses to exercise is the brevity of observation which is typically limited to sampling before, during and immediately after exercise. As ghrelin, and indeed several other appetite hormones, are regulators of the overall meal response, to capture the more meaningful effect of exercise on ghrelin it is necessary to assess extended responses to exercise and feeding. To this end we examined ghrelin responses to 90 min of moderate-high intensity running with frequent assessment of plasma acylated ghrelin during and for an 8.5 h period after exercise, and once on the following morning (King et al., 2010a). Given the intricate relationship between ghrelin and energy balance we hypothesised that ghrelin would be suppressed during exercise, but would increase in the hours thereafter as a compensatory mechanism to promote the restoration of energy balance. 
Paradoxically, in this study, although we witnessed a transient suppression during and immediately after exercise, circulating concentrations of acylated ghrelin remained no different to control at any point throughout the remainder of the trials. Notably, acylated ghrelin values on the morning after exercise ( $24 \mathrm{~h}$ sample) were almost identical 302 between the exercise and control trials. This was despite participants expending approximately $5324 \mathrm{~kJ}$ during exercise. These findings indicate that acylated ghrelin is not sensitive to acute energy deficits induced by exercise. Such a lack of response is in line with the consensus that acute exercise does not immediately augment appetite perceptions (apart from the transient suppression) or energy intake (Blundell, Stubbs, Hughes, Whybrow, \& King, 2003; Martins et al., 2008), specifically on the day of exercise. This is in stark contrast to energy deficits induced through acute food restriction whereby rapid and marked compensatory appetite, energy intake and circulating acylated ghrelin responses occur (Hubert, King, \& Blundell, 1998; King et al., 2011a). Specifically, we directly compared circulating acylated ghrelin responses to identical acute energy deficits $(4280 \mathrm{~kJ})$ induced by exercise verses food restriction and observed a striking compensatory response following consumption of reduced energy meals (King et al., 2011a). Conversely, no such response was observed in response to 90 min of running performed at the very beginning of a $9 \mathrm{~h}$ trial (Figure 2). It would therefore appear that acutely, acylated ghrelin is sensitive to nutrient/energy ingestion exercise. 
322 There is evidence that females may be less likely to experience favourable changes in 323 body weight and/or composition in response to exercise training compared with males and it is possible that this is due to divergent hormonal responses to exercise (Hagobian \& Braun, 2010). Recent investigations have examined whether part of this discrepant response is related to effects on appetite regulatory hormones such as acylated ghrelin, however a recent study has shown that acute acylated ghrelin responses to moderatehigh intensity exercise do not differ between sexes (Hagobian et al., 2013). It is possible that larger energy deficits associated with consecutive days of exercise training are necessary before any sex differences emerge.

Although transient reductions in circulating acylated ghrelin have been consistently observed in response to moderate-high intensity bouts of exercise, the physiological relevance of this response is not clear. Supressed levels of acylated ghrelin have been found to correlate with supressed hunger ratings (Broom et al., 2007) suggesting a role of acylated ghrelin in mediating appetite responses to exercise. Whether acute changes in acylated ghrelin after exercise impact up on energy intake is questionable however, given the brevity of responses which typically revert to control values within $30 \mathrm{~min}$ post-exercise (King et al., 2010a; Wasse et al., 2012, Wasse et al., 2013). Furthermore, after exercise, circulating pre-meal concentrations of acylated ghrelin do not correlate with subsequent ad libitum energy intake (King et al., 2010a; Deighton et al., 2012). Relative energy intake (energy intake corrected for the energy cost of exercise) is an important concept within energy balance research and our group recently examined the relation between exercise, acylated ghrelin and relative energy intake (Deighton et al, 2012). In this study we observed no association between acylated ghrelin and relative energy intake. Taken collectively, these data suggest that transient changes in acylated 
ghrelin with exercise are not tightly linked to changes in absolute or relative energy

intake. It is likely that within the short-term other behavioural, psychological or habitual

factors have a stronger impact on energy intake/food choices.

The mechanism(s) responsible for producing transient perturbations in circulating acylated ghrelin with exercise are not clear but must be related to either interference in the production of acylated ghrelin and/or its secretion into the circulation e.g. via effects on GOAT activity within the golgi apparatus, or augmentation of de-acylation by circulating proteases/esterases (De Vries et al., 2004). Findings demonstrating amplified acylated ghrelin suppression when exercising in the heat as compared with a thermoneutral climate (Shorten, Wallman, \& Guelfi, 2009) may implicate attenuated blood flow to the splanchnic regions and/or exertion related stress responses as key mediating mechanisms. Further research is needed to clarify this issue.

\section{Unacylated ghrelin}

The influence of acute exercise on circulating unacylated ghrelin has been determined recently. Using a sample of young, healthy males, Shiiya et al (2011) collected blood samples before, frequently during, and $90 \mathrm{~min}$ after one hour of moderate intensity cycling (50\% $\dot{\mathrm{V}} \mathrm{O}_{2}$ max). Acylated and unacylated ghrelin were assessed using enzymelinked immunosorbant assays specific for each peptide variant. Baseline levels of unacylated ghrelin were $\sim 6$ fold higher than acylated ghrelin. During exercise, circulating acylated ghrelin was suppressed by approximately 55\% however levels of unacylated ghrelin did not change at any point. These data support those relating to the acylated ghrelin literature and suggest that exercise somehow interferes with the acylation of ghrelin, rather than affecting unacylated ghrelin. The authors of this study 
suggest that gastric mucosal ischaemia and/or increased sympathetic nerve activity may mediate these effects on ghrelin acylation.

\section{Exercise Training}

Ghrelin (total)

Several studies have investigated the impact of exercise training (predominantly aerobic) on circulating levels of ghrelin, acylated ghrelin and unacylated ghrelin. Interpreting these outcomes is challenging given stark differences between studies in terms of the designs implemented, the participant groups examined and the methods utilised.

Ravussin, Tschöp, Morales, Bouchard, \& Heiman (2001) were the first to report findings regarding the impact of exercise training on circulating ghrelin. These researchers reported that a 93 day cycling intervention (2 bouts of cycling per day to expend $4184 \mathrm{~kJ} /$ day) with associated weight loss (6\%) led to a 26\% increase in fasting plasma ghrelin concentration within a sample of healthy, young, men. Conversely, chronic overfeeding (351,456 kJ) over 100 days, sufficient to raise body mass by 13\% led to a significant decrease (18\%) in fasting ghrelin. These findings indicate that ghrelin is highly responsive to changes in energy balance/body weight and this finding has been corroborated by others (Garcia et al., 2006). Conversely, one study reported that fasting and meal related circulating ghrelin levels remained unchanged despite 5\% weight loss induced by food restriction and exercise in a group of morbidly obese men and women (Morpurgo et al., 2003). This information may suggest that a threshold exists before changes in ghrelin are seen in response to weight loss interventions which is likely mediated by factors such as sex, baseline weight status and insulinaemia. 
It is thought that one of the primary functions of ghrelin is to regulate food intake on a meal to meal basis. Consequently, to understand how interventions impact on ghrelin it is essential to examine ghrelin responses before and after meals rather than merely assessing fasting levels. To address this, Leidy, Dougherty, Frye, Duke, \& Williams (2007) performed $24 \mathrm{~h}$ blood sampling in a small group of normal weight women, before and after a 12 week combined exercise and dietary intervention. In this study participants performed moderate-intensity aerobic exercise five times per week for approximately $45 \mathrm{~min} /$ session. Dietary intake was also decreased by a quarter. The intervention reduced body weight by $\sim 4 \%$ and this was associated with significantly ensuing weight loss augment the ghrelin diurnal profile.

\section{Insert figure 3 near here} weight loss. Leidy et al (2004) studied the impact of 12 weeks of exercise training on

417 fasting levels of ghrelin in a group of healthy, normal weight women. Participants completed moderate intensity aerobic exercise five times each week for a duration to expend $2092 \mathrm{~kJ} /$ session. Diet was controlled immaculately with all participant meals being provided by the research team. This study showed that exercise, without significant weight loss ( $<1.5 \mathrm{~kg})$ had no impact on fasting plasma ghrelin concentrations. 
422 Conversely, ghrelin levels increased two-fold in those who experienced significant 423 weight loss (> $1.5 \mathrm{~kg}$ ). These findings are supported by those of Foster-Schubert et al 424 (2005) who also observed augmented plasma levels of ghrelin only in participants who 425 experienced weight loss. Specifically, these researchers studied a large group of post426 menopausal women over 12 months. Half of the group exercised, performing moderate 427 intensity aerobic exercise five times each week, whilst the other participants were 428 randomised to control. Over the course of the intervention the exercise group lost weight (1.4 kg by 12 months) and this led to an increase in fasting plasma ghrelin concentrations $(\sim 5 \%)$. Importantly, more detailed analysis of the exercise group revealed that changes in ghrelin only occurred in those who lost body weight. Specifically, fasting ghrelin levels increased in a step-wise fashion, with greater changes being seen in those who lost a large amount of weight ( $>3 \mathrm{~kg}, 18 \%$ increase) compared with those who lost a moderate amount (0.5-3 kg, 7\% increase). Overall, the change in ghrelin was inversely associated with change in body weight $(r=-0.607)$. These findings have also been corroborated by others who reported that fasting levels of ghrelin did not change in response to 12 weeks of supervised moderate-intensity aerobic exercise training (five times per week) in a group of healthy, normal weight women who did not lose weight (Scheid, De Souza, Leidy, \& Williams, 2011). Conversely, fasting ghrelin levels increased significantly $(\sim 25 \%)$ in an exercise group who lost weight (3.2 kg).

The mechanisms by which changes in energy balance/body mass impact on circulating ghrelin are not fully understood although the adiposity signals leptin and insulin appear to be important. Leptin is produced within adipocytes and circulating levels correlate directly with adipose tissue mass (Maffei et al., 1995). An inverse reciprocal 
relationship exists between leptin and ghrelin with studies having unveiled a direct inhibitory effect of leptin on the production of ghrelin (Kamegai et al., 2004). Changes

in circulating concentrations of ghrelin in response to deviations in body mass e.g. with

weight loss or gain, may therefore occur secondary to alterations in leptin. Insulin may also mediate some of the effects of adiposity on ghrelin (Williams and Cummings, 2005). Specifically, it has been shown that insulin resistance and hyperinsulinemia are inversely associated with circulating levels of ghrelin (McLaughlin et al., 2004) and this may represent one mechanism by which insulin is implicated in the homeostatic regulation of energy balance.

Exercise training \& acylated ghrelin

The influence of exercise training on acylated ghrelin has been investigated recently. Hagobian et al (2009) examined acylated ghrelin responses to meal challenges before and after four consecutive days of exercise. Participants were previously sedentary, overweight or obese men and women and each completed two, four day trials in a crossover fashion. In both trials participants performed daily aerobic exercise to expend $\sim 30 \%$ of daily energy expenditure. In one trial participants replaced the energy expended during exercise by increasing their energy intake, whilst in the other condition no dietary changes were made, resulting in an energy deficit. Interestingly, these researchers observed augmented circulating levels of acylated ghrelin after the

467 intervention in females independent of the condition. This outcome suggests that exercise may independently trigger a compensatory acylated ghrelin response in females. In males, neither intervention had an influence on acylated ghrelin and it is possible that this divergent response may indicate the presence of a tighter homeostatic control 
471 system in females than males (Hagobian \& Braun, 2010). Further research is necessary 472 to confirm this.

Martins, Kulseng, King, Holst, \& Blundell (2010) also reported findings regarding the acylated ghrelin response to exercise training. In this study overweight/obese men and women completed supervised moderate-intensity aerobic exercise training five times 477 per week for 12 weeks. Acylated ghrelin responses to standardised meal challenges were examined before and after the intervention. In accordance with previous reports describing suppressed fasting and meal related changes in ghrelin in obese individuals (Cummings et al., 2002; English et al., 2002; Tschöp et al., 2001), circulating acylated ghrelin levels were low and unresponsive to meals before the intervention. After the intervention fasting levels of acylated ghrelin were increased and this was associated with greater meal related suppression. This change may indicate a beneficial response i.e. enhanced sensitivity to nutrient intake may represent improved appetite control. Notably, this response is consistent with previous data suggesting that exercise training in this population has a dual effect on appetite by increasing fasting hunger and enhancing satiety (King et al, 2009).

In the study of Martins et al (2010) participants maintained their usual diet and consequently lost weight during the course of the study. It is therefore impossible to determine whether these changes in acylated ghrelin dynamics were due to exercise itself or to weight loss. In contrast to these results, Guelfi, Donges, \& Duffield (2012) recently reported that acylated ghrelin fasting levels and meal related profiles do not change in response to exercise training. These researchers studied a cohort of overweight or obese men who were allocated to control, aerobic or resistance training 
496 (three times per week) for 12 weeks. The aerobic training group lost $\sim 2 \mathrm{~kg}$ whilst

497 weight did not change amongst the resistance training group. Nonetheless, circulating 498 levels of acylated ghrelin did not change in either group. Differential outcomes between 499 this investigation and that of Martins et al (2010) may be due to differences in study 500 participants i.e. whether both men and women were included, meal challenges imposed 501 (the latter study used an oral glucose challenge as a stimulus), training frequency (five vs. three times per week) and associated weight loss. Further research is therefore needed to isolate the influence of exercise training on circulating acylated ghrelin, however we may speculate that as for ghrelin, changes will possibly only occur secondary to perturbations in body weight.

506

507

Exercise training \& unacylated ghrelin

508

The effect of exercise training on circulating unacylated ghrelin concentrations was investigated in a prospective study during which 552 young Finnish men completed six months of military training (Cederberg et al., 2011). In this investigation the authors reported a significant increase in circulating unacylated ghrelin which was weakly inversely associated with changes in body weight, waist circumference and fat mass. Although this study provides a useful starting point for future work investigating the interaction between exercise training and unacylated ghrelin, unfortunately the lack of control over training volume, dietary intake and body weight change make it impossible to derive any concrete inferences from the study.

517

\section{Conclusions and future directions}

519 The first studies to investigate the interaction between exercise and ghrelin were 520 published approximately a decade ago. Outcomes reported from several early 
experiments produced a confused picture with reports of acute increases, decreases and

522

523

524 no change in circulating ghrelin. More recently, with the development of more sensitive assay methodologies, investigators have specifically focused on the individual responses of acylated and unacylated ghrelin to exercise. A large body of data suggests that circulating levels of acylated ghrelin are transiently suppressed in response to acute exercise when performed at moderate intensities or higher. This effect is independent of exercise mode and lasts for approximately 30 min after exercise. After this period no further changes in acylated ghrelin occur on the day when exercise is performed i.e. there is no increase or compensation in acylated ghrelin. Limited data available indicates that circulating levels of unacylated ghrelin do not change with acute exercise.

Collectively, it appears that transient changes in ghrelin in response to acute exercise are related to interference with the production of the acylated form of ghrelin. Further research is needed (with more consistent methods i.e. control of participants' pre-trial diet, sample collection/processing procedures, assay protocols) to confirm the impact of exercise on the individual ghrelin variants. Additional work is also needed to define the mechanisms responsible for changes in acylated ghrelin with acute exercise.

Data regarding the influence of exercise training on ghrelin is more consistent and clearly illustrates that exercise training per se has no impact on circulating levels of ghrelin. Instead, changes in ghrelin that are seen over the course of exercise interventions take place secondary to weight loss. This response likely represents a physiological mechanism seeking to defend energy homeostasis. The impact of exercise training on acylated and unacylated ghrelin has received less attention with insufficient data available to derive any meaningful conclusions regarding unacylated ghrelin. The limited findings regarding the effects on acylated ghrelin are mixed, but may suggest 
that exercise training with associated weight loss improves the acylated ghrelin satiety

547 response to meals in overweight and obese individuals. Moreover, one study suggests that exercise training may exert an independent compensatory effect on acylated ghrelin in females. Additional research is needed however to conclusively determine the extent of sex differences in ghrelin regulation and to determine the independent influence of exercise training (various modes) on the dual circulating ghrelin forms.

552

553 Finally, although this review has focused solely on ghrelin, it is important to note that 554 there are several additional hormones that are involved in the acute and chronic 555 regulation of appetite and energy balance e.g. Peptide YY, glucagon-like-peptide 1, cholekystokinin and leptin. Future research must take a holistic approach and take into 557 account the wider impact of interventions on this hormonal system. Additionally, although this review has focused on ghrelin, it is also important to highlight that food intake/energy balance is not solely governed by homeostatic forces but is also influenced significantly by non-homeostatic factors which may be physiological (Evero, Hackett, Clark, Phelan \& Hagobian, 2012, Westerterp-Plantenga, Verwegen, Ijedema, Wijckmans \& Saris, 1997) cognitive/behavioural (Blundell \& Gillett, 2001), social (de Castro, 1990) or environmental (Hill, Wyatt, Reed \& Peters, 2003). These influences have the potential to override homeostatic regulators (Berthoud, 2004; Borer, 2010) and must therefore always be considered in the context of food intake regulation.

567 Acknowledgements

568 The research was supported by the National Institute for Health Research (NIHR) Diet, 569 Lifestyle \& Physical Activity Biomedical Research Unit based at University Hospitals 
of Leicester and Loughborough University. The views expressed are those of the authors and not necessarily those of the NHS, the NIHR or the Department of Health.

\section{References}

Asakawa, A., Inui, A., Kaga, T., Katsuura, G., Fujimiya, M., Fujino, M.A., Kasuga, M. (2003). Antagonism of the ghrelin receptor reduces food intake and body weight of mice. Gut, 52, 947-952.

Asakawa, A., Inui, A., Fujimiya, M., Sakamaki, R., Shinfuku, N., Ueta, Y., Meguid, M.M., Kasuga, M. (2005). Stomach regulates energy balance by acylated and desacyl ghrelin. Gut, 54, 18-24.

Arvat, E., Maccario, M., Di Vito, L., Broglio, F., Benso, A., Gottero, C., Papotti, M., Muccioli, G., Dieguez, C., Casanueva, F.F., Deghenghi, R., Camanni, F., Ghigo, E. (2001). Endocrine activities of ghrelin, a natural growth hormone secretagogue (GHS), in humans: comparison and interactions with hexarelin, a nonnatural peptidyl GHS, and GH-releasing hormone. Journal of Clinical Endocrinology and Metabolism, 86, 11691174.

Ballard, T.P., Melby, C.L., Camus, H., Cianciulli, M., Pitts, J., Schmidt, S., Hickey, M.S. (2009). Effect of resistance exercise, with or without carbohydrate supplementation, on plasma ghrelin concentrations and postexercise hunger and food intake. Metabolism, 58, 1191-1199.

Berthoud HR. (2004). Neural control of appetite: cross-talk between homeostatic and non-homeostatic systems. Appetite, 43, 315-317. 
593

594

595

596

597

598

599

600

601

602

603

604

605

606

607

608

609

610

611

612

613

Blundell, J.E. Gillett, A. (2001). Control of food intake in the obese. Obes Res, 9, 263S270S.

Blundell, J.E., Stubbs, R.J., Hughes, D.A., Whybrow, S., King, N.A. (2003). Cross talk between physical activity and appetite control: does physical activity stimulate appetite? Proceedings of the Nutrition Society, 62, 651-661.

Borer, K.T. (2010). Nonhomeostatic control of human appetite and physical activity in regulation of energy balance. Exercise and Sport Science Reviews, 38, 114-121.

Broom, D.R., Batterham, R.L., King, J.A., \& Stensel, D.J. (2009). Influence of resistance and aerobic exercise on hunger, circulating levels of acylated ghrelin, and peptide YY in healthy males. American Journal of Physiology: Regulative Integrative and Comparative Physiology, 296, R29-35.

Broom, D.R., Stensel, D.J. (2006). The influence of exercise intensity on plasma acylated ghrelin. Journal of Sports Sciences, 25, 352-353.

Broom, D.R., Stensel, D.J., Bishop, N.C., Burns, S.F., \& Miyashita, M. (2007). Exercise-induced suppression of acylated ghrelin in humans. Journal of Applied Physiology, 102, 2165-2171.

Burns, S.F., Broom, D.R., Miyashita, M., Mundy, C., Stensel, D.J. (2007). A single session of treadmill running has no effect on plasma total ghrelin concentrations. Journal of Sports Sciences, 25, 635-642.

Callahan, H.S., Cummings, D.E., Pepe, M.S., Breen, P.A., Matthys, C.C., \& Weigle, D.S. (2004). Postprandial suppression of plasma ghrelin level is proportional to ingested 
614

615

616

617

618

619

620

621

622

623

624

625

626

627

628

629

630

631

632

633

634

caloric load but does not predict intermeal interval in humans. Journal of Clinical Endocrinology and Metabolism, 89, 1319-1324.

Cederberg, H., Rajala, U., Koivisto, V.M., Jokelainen, J., Surcel, H.M., Keinänen-

Kiukaanniemi, S., Laakso, M. (2011). Unacylated ghrelin is associated with changes in body composition and body fat distribution during long-term exercise intervention. European Journal of Endocrinology, 165, 243-248.

Chandarana, K., Drew, M.E., Emmanuel, J., Karra, E., Gelegen, C., Chan, P., Cron, N.J., Batterham, R.L. (2009). Subject standardisation, acclimatisation, and sample processing affect gut hormone levels and appetite in humans. Gasteroenterology, 136, 2115-2126.

Christ, E.R., Zehnder, M., Boesch, C., Trepp, R., Mullis, P.E., Dien, P., Décombaz, J. (2006). The effect of increased lipid intake on hormonal responses during aerobic exercise in endurance-trained men. European Journal of Endocrinology, 154, 397-403.

Cummings, D.E., Purnell, J.Q., Frayo, R.S., Schmidova, K., Wisse, B.E., \& Weigle, D.S. (2001). A preprandial rise in ghrelin suggests a role in meal initiation in humans. Diabetes, 50, 1714-1719.

Cummings, D.E., Weigle, D.S., Frayo, R.S., Breen, P.A., Ma, M.K., Dellinger, E.P., Purnell, J.Q. (2002). Plasma ghrelin levels after diet-induced weight loss or gastric bypass surgery. The New England Journal of Medicine, 346, 1623-1630.

Dall, R., Kanaley, J., Hansen, T.K., Moller, N., Christiansen, J.S., Hosoda, H., Kangawa, K., Jorgensen, J.O. (2002). Plasma ghrelin levels during exercise in healthy subjects and in growth hormone deficient patients. European Journal of Endocrinology, 147, 65-70. 
638

639

640

641

642

643

644

645

646

647

648

649

650

651

652

653

654

655

656

De Castro, J.M. (1990). Social facilitation of duration and size but not rate of the spontaneous meal intake of humans. Physiol Behav, 47, 1129-1135.

Deighton, K., Barry, R., Connon, C.E., Stensel, D.J. (2012). Appetite, gut hormone and energy intake responses to low volume sprint interval and traditional endurance exercise. European Journal of Applied Physiology, Oct 31 ${ }^{\text {st }}$ [Epub ahead of print]

Delhanty, P.J.D., Neggers, S.J., van der Lely, A.J. (2012). Ghrelin: the differences between acyl-and des-acyl ghrelin. European Journal of Endocrinology, 167, 601-608.

Delhanty PJ, van der Lely AJ. (2011). Ghrelin and glucose homeostasis. Peptides, 32, 2309-2318.

De Vriese, C., Gregoire, F., Lema-Kisoka, R., Waelbroeck, M., Robberecht, P., Delporte, C. (2004). Ghrelin degradation by serum and tissue homogenates: identification of the cleavage sites. Endocrinology, 145, 4997-5005.

Druce, M.R., Neary, N.M., Small, C.J., Milton, J., Monteiro, M., Patterson, M., Ghatei, M.A., Bloom, S.R. (2006). Subcutaneous administration of ghrelin stimulates energy intake in healthy lean volunteers. International Journal of Obesity (Lond), 30, 293-296.

Druce, M.R., Wren, A.M., Park, A.J., Milton, J.E., Patterson, M., Frost, G., Ghatei, M.A., Small, C., Bloom, S.R. (2005). Ghrelin increases food intake in obese as well as lean participants. International Journal of Obesity (Lond), 29, 1130-1136. 
657 Egecioglu, E., Jerlhag, E., Salomé, N., Skibicka, K.P., Haage, D., Bohlooly-Y. M., 658 Andersson, D., Bjursell, M., Perrissoud, D., Engel, J.A., Dickson, S.L. (2010). Ghrelin 659 increases intake of rewarding food in rodents. Addition Biology, 15, 304-311.

660 English, P.J., Ghatei, M.A., Malik, I.A., Bloom, S.R., Wilding, J.P. Food fails to 661 suppress ghrelin levels in obese humans. (2002). Journal of Clinical Endocrinology and 662 Metabolism, 87, 2984.

663

Erdmann, J., Tahbaz, R., Lippl, F., Wagenpfeil, S., Schusdziarra, V. (2007). Plasma 664 ghrelin levels during exercise - effects of intensity and duration. Regulatory Peptides, 665 143, 127-135.

Evero, N., Hackett, L.C., Clark, R.D., Phelan, S., \& Hagobian, T.A. (2012). Aerobic exercise reduces neuronal responses in food reward brain regions. Journal of Applied Physiology, 112, 1612-1619.

Foster-Schubert, K.E., McTiernan, A., Frayo, R.S., Schwartz, R.S., Rajan, K.B., Yasui, Y., Tworoger, S.S., Cummings, D.E. (2005). Human plasma ghrelin levels increase during a one-year exercise program. Journal of Clinical Endocrinology and Metabolism, 90, 820-825.

673 Galbo, H., Christensen, N.J., Holst, J.J (1977). Catecholamines and pancreatic

674 hormones during autonomic blockade in exercising man. Acta Physiologica

675 Scandinavica, 101, 428-437.

676 Garcia. J.M., Iyer, D., Poston, W.S., Marcelli, M., Reeves, R., Foreyt, J., 677 Balasubramanyam, A. (2006). Rise of plasma ghrelin with weight loss is not sustained 678 during weight maintenance. Obesity (Silver Spring), 14, 1716-23. 
679 Ghanbari-Niaki, A. (2006). Ghrelin and glucoregulatory hormone responses to a single 680 circuit resistance exercise in male college students. Clinical Biochemistry, 39, 966-970.

681 Godfrey, R.J., Madgwick, Z., Whyte, G.P. (2003). The exercise-induced growth 682 hormone response in athletes. Sports Medicine, 33, 599-613.

683 Guelfi, K.J., Donges, C.E., Duffield, R. (2012). Beneficial effects of 12 weeks of 684 aerobic compared with resistance exercise training on perceived appetite in previously 685 sedentary overweight and obese men. Metabolism, Sep 6. [Epub ahead of print]

686 Gutierrez, J.A., Solenberg, P.J., Perkins, D.R., Willency, J.A., Knierman, M.D., Jin, Z., 687 Witcher, D.R., Luo, S., Onyia, J.E., Hale, J.E. (2008). Ghrelin Octanoylation mediated 688 689 6320-6325.

Hagobian, T.A, Braun, B. (2010). Physical activity and hormonal regulation of appetite: 691 sex differences and weight control. Exercise and Sports Science Reviews, 38, 25-30.

692

Hagobian, T.A., Sharoff, C.G., Stephens, B.R., Wade, G.N., Silva, J.E., Chipkin, S.R., 693 \& Braun, B. (2009). Effects of exercise on energy-regulating hormones and appetite in 694 men and women. American Journal of Physiology: Regulative Integrative and 695 Comparative Physiology, 296, R233-R242.

696 Hagobian, T., Yamashhiro, M., Hinkel-Lipsker, J., Streder, K., Evero, N., Hackney, T. 697 (2013). Effects of acute exercise on appetite hormones and ad libitum energy intake in men and women. Applied Physiology, Nutrition and Metabolism, 38, 66-72. hormone. Annals of Medicine, 39, 116-136. 
Hill, J.O., Wyatt, H.R., Reed, G.W., Peters, J.C. Obesity and the environment: where do we go from here? Science, 299, 853-855.

Hosoda, H., Doi, K., Nagaya, N., Okumura, H., Nakagawa, E., Enomoto, N., Ono, F., Kangawa, K. (2004). Optimum collection and storage conditions for ghrelin measurements: octanoyl modification of ghrelin is rapidly hydrolyzed to desacyl ghrelin in blood samples. Clinical Chemistry, 50, 1077-1080.

Hubert, P., King, N.A., \& Blundell, J.E. (1998). Uncoupling the effects of energy expenditure and energy intake: appetite response to short-term energy deficit induced by meal omission and physical activity. Appetite, 31, 9-19.

Jürimäe, J., Hofmann, P., Jürimäe,T., Palm, R., Mäestu, J., Purge, P., Sudi, K., Rom, K., von Duvillard, S.P. (2007a). Plasma ghrelin responses to acute sculling exercises in elite male rowers. European Journal of Applied Physiology, 99, 467-474.

Jürimäe, J., Jürimäe, T., Purge, P. (2007b). Plasma ghrelin is altered after maximal exercise in elite male rowers. Experimental Biology and Medicine (Maywood), 232, 904-909.

Jürimäe, J., Rämson, R., Mäestu, J., Purge, P., Jürimäe, T., Arciero, P.J., von Duvillard, S.P. (2009). Plasma visfatin and ghrelin responses to prolonged sculling in competitive male rowers. Medicine and Science in Sports and Exercise, 41, 137-143.

Kallio, J., Pesonen, U., Karvonen, M.K., Kojima, M., Hosoda, H., Kangawa, K. (2001). Enhanced exercise-induced GH secretion in subjects with Pro7 substitution in the prepro-NPY. Journal of Clinical Endocrinology and Metabolism, 86, 5348-5352. 
Kamegai, J., Tamura, H., Shimizu, T., Ishii, S., Sugihara H., Oikawa, S. (2004). Effects

of insulin, leptin, and glucagon on ghrelin secretion from isolated perfused rat stomach. Regulatory Peptides, 119, 77-81.

King, N.A., Burley, V.J., Blundell, J.E. (1994). Exercise-induced suppression of appetite: effects on food intake and implications for energy balance. European Journal of Clinical Nutrition, 48, 715-724.

King, N.A., Caudwell, P.P., Hopkins, M., Stubbs, J.R., Naslund, E., Blundell, J.E. (2009). Dual-process action of exercise on appetite control: increase in orexigenic drive but improvement in meal-induced satiety. American Journal of Clinical Nutrition, 90, 921-927.

King, J.A., Miyashita, M., Wasse, L.K., \& Stensel, D.J. (2010a). Influence of prolonged treadmill running on appetite, energy intake and circulating concentrations of acylated ghrelin. Appetite, 54, 492-498.

King, J.A., Wasse, L.K., Broom, D.R., Stensel, D.J. (2010b). Influence of brisk walking on appetite, energy intake, and plasma acylated ghrelin. Medicine \& Science in Sports \& Exercise, 42, 485-492.

King, J.A., Wasse, L.K., Ewens, J., Crystallis, K., Emmanuel, J., Batterham, R.L., \& Stensel, D.J.(2011a). Differential acylated ghrelin, Peptide YY3-36, appetite and food intake responses to equivalent energy deficits created by exercise and food restriction. Journal of Clinical Endocrinology and Metabolism. 96, 1114-1121. 
742 King, J.A., Wasse, L.K., \& Stensel, D.J. (2011b). The acute effects of swimming on 743 appetite, food intake and plasma acylated ghrelin. Journal of Obesity, pii: 351628. 744 DOI:10.1155/2011/351628

745 King, N.A., Caudwell, P.P., Hopkins, M., Stubbs, J.R., Naslund, E., Blundell, J.E. 746 (2009). Dual-process action of exercise on appetite control: increase in orexigenic drive 747 but improvement in meal-induced satiety. American Journal of Clinical Nutrition, 90, $748 \quad 921-927$.

749 Kojima, M. (2008). The discovery of ghrelin--a personal memory. Regulatory Peptides, $750 \quad 145,2-6$.

751 Kojima, M., Hosoda, H., Date, Y., Nakazato, M., Matsuo, H., Kangawa, K. (1999).

752 Ghrelin is a growth-hormone releasing acylated peptide from stomach. Nature, 402, $753 \quad 656-660$.

754 Kojima, M., Hosoda, H., Matsuo, H., Kangawa, K. (2001). Ghrelin: discovery of the 755 natural endogenous ligand for the growth hormone secretagogue receptor. Trends in 756 Endocrinology and Metabolism, 12, 118-126.

757 Kojima, M., Kangawa, K. (2005). Ghrelin: structure and function. Physiology Reviews, $758 \quad 85,495-522$.

759 Kraemer, R.R., Durand, R.J., Acevedo, E.O., Johnson, L.G., Kraemer, G.R., Hebert, 760 E.P., Castracane, V.D. (2004a). Rigorous running increases growth hormone and 761 insulin-like growth factor-I without altering ghrelin. Experimental Biology and 762 Medicine (Maywood), 229, 240-246. 
763 Kraemer, R.R., Durand, R.J., Hollander, D.B., Tryniecki, J.L., Herbert, E.P., Castracane,

764 V.D. (2004b). Ghrelin and other glucoregulatory hormone responses to eccentric and 765 concentric muscle contractions. Endocrine, 24, 93-98.

766 Leidy, H.J., Dougherty, K.A., Frye, B.R., Duke, K.M., Williams, N.I. (2007). Twenty767 four hour ghrelin is elevated after calorie restriction and exercise training in non-obese 768 women. Obesity, 15, 446-455.

Leidy, H.J., Gardner, J.K., Frye, B.R., Snook, M.L., Schuchert, M.K., Richard, E.L., Williams, N.I. (2004). Circulating ghrelin is sensitive to changes in body weight during 771 a diet and exercise program in normal-weight young women. The Journal of Clinical Endocrinology and Metabolism, 89, 2659-2664.

Leidy, H.J., \& Williams, N.I. (2006). Meal energy content is related to features of mealrelated ghrelin profiles across a typical day of eating in non-obese premenopausal women. Hormone and Metabolic Research, 38, 317-322.

Le Roux, C.W, Patterson, M., Vincent, R.P., Hunt, C., Ghatei, M.A., Bloom, S.R. 777 (2005). Postprandial plasma ghrelin is suppressed proportional to meal calorie content in normal-weight but not obese subjects. Journal of Clinical Endocrinology and Metabolism, 90, 1068-1071.

Levin F, Edholm T, Schmidt PT, Grybäck P, Jacobsson H, Degerblad M, Höybye C, 781 Holst JJ, Rehfeld JF, Hellström PM, Näslund E. (2006). Ghrelin stimulates gastric emptying and hunger in normal-weight humans. Journal of Clinical endocrinology and Metabolism, 91, 3296-3302. 
Liu, J., Prudom, C.E., Nass, R., Pezzoli, S.S., Oliveri, M.C., Johnson, M.L., Veldhuis, P., Gordon, D.A., Howard, A.D., Witcher, D.R., Getsen, H.M., Gaylinn, B.D., Thorner, M.O. (2008). Novel ghrelin assays provide evidence for independent regulation of ghrelin acylation and secretion in healthy young men. Endocrine Research, 93, 19801987.

Maffei, M., Halaas, J., Ravussin, E., Pratley, R.E., Lee, G.H., Zhang, Y., Fei, H., Kim,

S., Lallone, R., Ranganathan, S., et al. (1995). Leptin levels in human and rodent:

measurement of plasma leptin and ob RNA in obese and weight-reduced subjects.

Nature Medicine, 1, 1155-1161.

Malik, S., McGlone, F., Bedrossian, D., Dagher, A. (2008). Ghrelin modulates brain activity in areas that control appetite behaviour. Cell Metabolism, 7, 4000-4009.

Malkova, D., McLaughlin, R., Manthou, E., Wallace, A.M., \& Nimmo, M.A. (2008). Effect of moderate-intensity exercise session on preprandial and postprandial responses of circulating ghrelin and appetite. Hormone and Metabolic Research, 40, 410-415.

Martins, C., Kulseng, B., King, N.A., Holst, J.J., Blundell, J.E. (2010). The effects of exercise-induced weight loss on appetite-related peptides and motivation to eat. The Journal of Clinical Endocrinology and Metabolism, 95, 1609-1616.

Martins, C., Morgan, L.M., Bloom, S.R., \& Robertson, M.D. (2007). Effects of exercise on gut peptides, energy intake and appetite. Journal of Endocrinology, 193, 251-258.

Martins, C., Morgan, L., \& Truby, H. (2008). A review of the effects of exercise on appetite regulation: an obesity perspective. International Journal of Obesity, 32, 13371347. 
Plasma ghrelin concentrations are decreased in insulin-resistant obese adults relative to equally obese insulin-sensitive controls. Journal of Clinical Endocrinology and Metabolism, 89, 1630-1635.

Morpurgo, P.S., Resnik, M., Agosti, F., Cappiello, V., Sartorio, A., Spada, A. (2003).

Ghrelin secretion in severely obese subjects before and after a 3-week integrated body mass reduction program. Journal of Endocrinological Investigation, 26, 723-727.

Muccioli, G., Lorenzi, T., Lorenzi, M., Ghè, C., Arnoletti, E., Raso, G.M., Castellucci, M., Gualillo, O., Meli, R. (2011). Beyond the metabolic role of ghrelin: a new player in the regulation of reproductive function. Peptides, 32, 2514-2521. H., Shimizu, W., Yamagishi, M., Oya, H., Koh, H., Yutani, C., Kangawa, K. (2001). Elevated circulating levels of ghrelin in cachexia associated with chronic heart failure: relationships between ghrelin and anabolic/catabolic factors. Circulation, 104, 20342038.

Nakazato, M., Murakami, N., Date, Y., Kojima, M., Matsuo, H., Kangawa, K., Matsukura, S. (2001). A role for ghrelin in the central regulation of feeding. Nature, 409, 194-198.

824 Perello, M., Sakata, I., Birnbaum, S., Chuang, J.C., Osborne-Lawrence, S., Rovinsky, the rewarding value of high-fat diet in an orexin-dependent manner. Biological

827 Psychiatry, 67, 880-886. 
Pfluger, P.T., Kirchner, H., Günnel, S., Schrott, B., Perez-Tilve, D., Fu, S., Benoit, S.C., Horvath, T., Joost, H.G., Wortley, K.E., Sleeman, M.W., Tschöp, M.H. (2008). Simultaneous deletion of ghrelin and its receptor increases motor activity and energy expenditure. American Journal of physiology: Gastrointestinal and Liver Physiology, 294, G610-618.

Ravussin, E., Tschöp, M., Morales, S., Bouchard, C., Heiman, M.L. (2001). Plasma ghrelin concentration and energy balance: overfeeding and negative energy balance studies in twins. The Journal of Clinical Endocrinology and Metabolism, 26, 723-727.

Scheid, J.L., De Souza, M.J., Leidy, H.J., Williams, N.I. (2011). Ghrelin but not peptide YY is related to change in body weight and energy availability. Medicine and Science in Sports and Exercise, 43, 2063-2071.

Schellekens, H., Dinan, T.G., Cryan, J.F. (2010). Lean mean fat reducing "ghrelin" machine: hypothalamic ghrelin and ghrelin receptors as therapeutic targets in obesity. Neuropharmacology, 58, 2-16.

Schmidt A, Maier C, Schaller G. (2004). Acute exercise has no effect on ghrelin plasma concentrations. Hormone and Metabolic Research, 36, 174-177.

Shiiya, T., Nakazato, M., Mizuta, M., Date, Y., Mondal, M.S., Tanaka, M., Nozoe, S., Hosoda, H., Kangawa, K., Matsukura, S. (2002). Plasma ghrelin levels in lean and obese humans and the effect of glucose on ghrelin secretion. Journal of Clinical Endocrinology and Metabolism, 87, 240-244.

Shiiya, T., Ueno, H., Toshinai, K., Kawagoe, T., Naito, S., Tobina, T., Nishida, Y., Shindo, M., Kangawa, K., Tanaka, H., Nakazato, M. (2011). Significant lowering of 
850

851

852

853

854

855

856

857

858

859

860

861

862

863

864

865

866

867

868

869

870

871

plasma ghrelin but not des-acyl ghrelin in response to acute exercise in men. Endocrine Journal, 58, 335-342.

Shintani, M., Ogawa, Y., Ebihara, K., Aizawa-Abe, M., Miyanaga, F., Takaya, K., Hayashi, T., Inoue, G., Hosoda, K., Kojima, M., Kangawa, K., Nakao, K. (2001). Ghrelin, an endogenous growth hormone secretagogue, is a novel orexigenic peptide that antagonizes leptin action through the activation of hypothalamic neuropeptide Y/Y1 receptor pathway. Diabetes, 50, 227-232.

Shimbara T, Mondal MS, Kawagoe T, Toshinai K, Koda S, Yamaguchi H, Date Y, Nakazato M. (2004). Central administration of ghrelin preferentially enhances fat ingestion. Neuroscience Letters, 369, 75-79.

Shorten, A.L., Wallman, K.E., Guelfi, K.J. (2009). Acute effect of environmental temperature during exercise on subsequent energy intake in active men. American Journal of Clinical Nutrition, 90, 1215-1221.

Stengel, A., Goebel, M., Wang, L., Taché, Y. (2010). Ghrelin, des-acyl ghrelin and nesfatin-1 in gastric X/A-like cells: role as regulators of food intake and body weight. Peptides, 31, 357-369.

Stengel, A., Taché, Y. (2012). Ghrelin - a pleiotropic hormone secreted from x/a like cells of the stomach. Frontiers of Neuroscience, 6:24. doi: 10.3389/fnins.2012.00024. Epub 2012 Feb 16.

Tack, J., Depoortere, I., Bisschops, R., Delporte, C., Coulie, B., Meulemans, A., Janssens, J., Peeters, T. (2006). Influence of ghrelin on interdigestive gastrointestinal motility in humans. Gut, 55, 327-333. 
872 Taub, D.D. (2008). Novel connections between the neuroendocrine and immune 873 systems: the ghrelin immunoregulatory network. Vitamins and Hormones, 77, 325-346.

874 Toshinai, K., Kawagoe, T., Shimbara, T., Tobina, T., Nishida, Y., Mondal, M.S., 875 Yamaguchi, H., Date, Y., Tanaka, H., Nakazato, M. (2007). Acute incremental exercise 876 decreases plasma ghrelin level in healthy men. Hormone and Metabolic Research, 39, 877 849-851.

878

879 880

881

882

883

884

885

886

887

Tschöp, M., Weyer, C., Tataranni, P.A., Devanarayan, V., Ravussin, E., Heiman, M.L. (2001). Circulating ghrelin levels are decreased in human obesity. Diabetes, 50, 707709.

Ueda, S., Yoshikawa, T., Katsura, Y., Usui, T., Nakao, H., Fujimoto, S. (2009). Changes in gut hormones levels in negative energy balance during aerobic exercise in obese young males. The Journal of Endocrinology, 201, 151, 159.

Vendrell, J., Broch, M., Vilarrasa, N., Molina, A., Gómez, J.M., Gutiérrez, C., Simón, I., Soler, J., Richart, C. (2004). Resistin, adiponectin, ghrelin, leptin, and proinflammatory cytokines: relationships in obesity. Obesity Research, 12, 962-971.

Vestergaard, E.T., Dall, R., Lange, K.H., Kjaer, M., Christiansen, J.S., Jorgensen, J.O. (2007). The ghrelin response to exercise before and after growth hormone administration. Journal of Clinical Endocrinology and Metabolism, 92, 297-303.

Vlasova, M.A., Järvinen, K., Herzig, K.H. (2009). Cardiovascular effects of ghrelin antagonists in conscious rats. Regulatory Peptides, 156, 72-76. 
Wagenmakers, A.J., Beckers, E.J., Brouns, F., Kuipers, H., Soeters, P.B., van der Vusse, G.J., Saris, W.H. (1991). Carbohydrate supplementation, glycogen depletion, and amino acid metabolism during exercise. The American Journal of Physiology, 260, E833-E890.

Wasse, L.K., Sunderland, C., King, J.A., Batterham, R.L., \& Stensel, D.J. (2012). Influence of rest and exercise at a simulated altitude of $4000 \mathrm{~m}$ on appetite, energy intake, and plasma concentrations of acylated ghrelin and peptide YY. Journal of Applied Physiology,112, 552-559.

Wasse, L.K., Sunderland, C., King, J.A., Miyashita, M., Stensel, D.J. (2013).The influence of vigorous running and cycling exercise on hunger perceptions and plasma acylated ghrelin concentrations in lean young men. Applied Physiology, Nutrition and Metabolism, 38, $1-6$.

Westerterp-Plantenga, M.S., Verwegen, C.R., Ijedema, M.J.W., Wijckmans, N.E.G., \& Saris, W.H.S. (1997). Acute effects of exercise or sauna on appetite in obese and nonobese men. Physiology and Behaviour, 62, 1345-1354.

Williams, D.L., Cummings, D.E. (2005). Regulation of ghrelin in physiologic and pathological states. The Journal of Nutrition, 135, 1320-1325.

Wortley, K.E., Anderson, K.D., Garcia, K., Murray, J.D., Malinova, L., Liu, R., Moncrieffe, M., Thabet, K., Cox, H.J., Yancopoulos, G.D., Wiegand, S.J., Sleeman, M.W. (2004). Genetic deletion of ghrelin does not decrease food intake but influences metabolic fuel preference. Proceedings of the National Academy of Sciences in the United States of America, 101, 8227-8232. 
913 Wren, A.M., Cohen, M.A., Brynes, A.E., Frost, G.S., Murphy, K.G., Dhillo, W.S., 914 Ghatei, M.A., Bloom, S.R. (2001b). Ghrelin enhances appetite and increases food intake 915 in humans. Journal of Clinical Endocrinology and Metabolism, 86, 5992-5995.

916 Wren, A.M., Small, C.J., Abbott, C.R., Dhillo, W.S., Seal, L.J., Cohen, M.A., 917 Batterham, R.L., Taheri, S., Stanley, S.A., Ghatei, M.A., Bloom, S.R. (2001a). Ghrelin 918 causes hyperphagia and obesity in rats. Diabetes, 50, 2540-2547.

919 Wren, A.M., Small, C.J., Ward, H.L., Murphy, K.G., Dakin, C.L., Taheri, S., Kennedy, 920 A.R., Roberts, G.H., Morgan, D.G., Ghatei, M.A., Bloom, S.R. (2000). The novel 921 hypothalamic peptide ghrelin stimulates food intake and growth hormone secretion. 922 Endocrinology, 141, 4325-4328.

923 Yang, J., Brown, M.S., Liang, G., Grishin, N.V., Goldstein, J.L. (2008). Identification 924 of the acyltransferase that octanoylates ghrelin, appetite-stimulating peptide hormone. 925 Cell, 132, 387-396.

926

927

928

929

930

931

932

933 
935 Figure 1: Post-translational processing yielding acylated ghrelin via addition of medium 936 chain fatty acids to serine-3. Adapted from Kojima et al (1999).

937 Figure 2: Acute acylated ghrelin responses to identical energy deficits (4280 kJ) 938 induced by exercise and food restriction. NB: exercise performed 0-1.5 h. ${ }^{\text {adifferent }}$ 939 from Control $P<0.05$; ${ }^{b}$ different from exercise $P<0.05$. Values are mean $\pm \mathrm{SEM}(\mathrm{n}=$ 940 12). Data from King et al (2011a).

941 Figure 3: Circulating concentrations of total ghrelin before and after a 12 week diet and 942 exercise intervention producing a sustained negative energy balance and reduction in 943 body weight. * $P<0.05$. Values are mean \pm SEM $(n=8)$. Data from Leidy et al, (2007). 


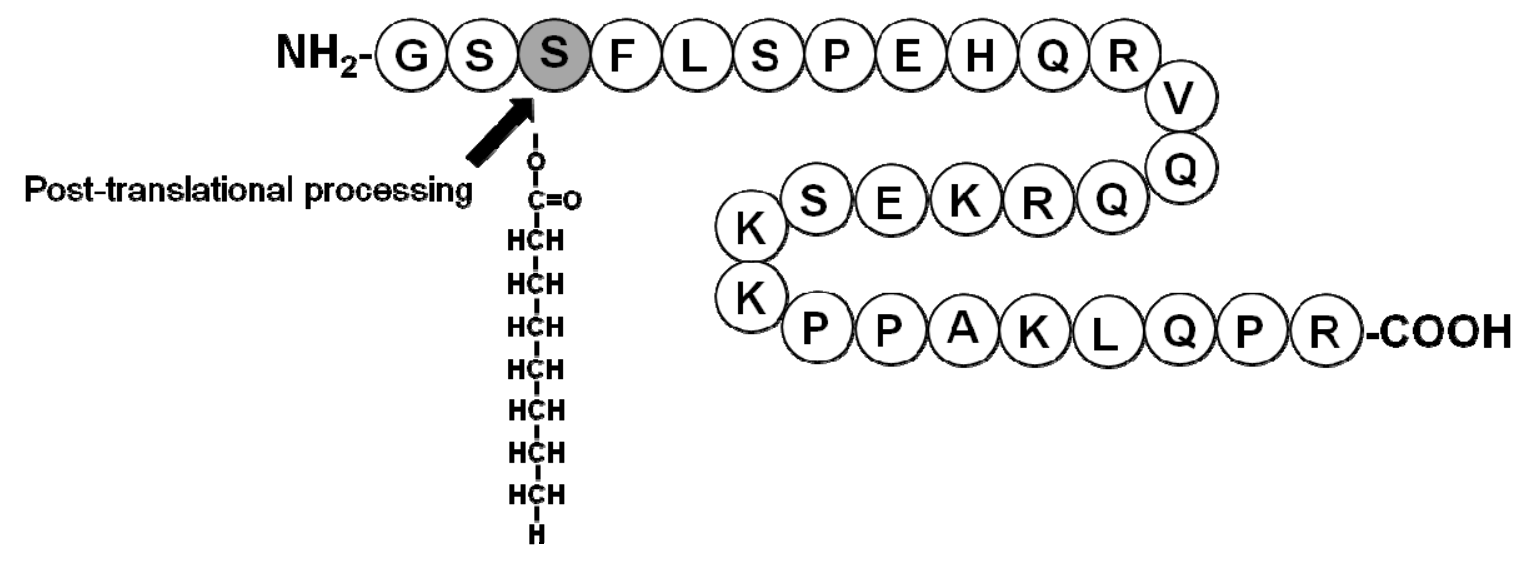

Figure 2

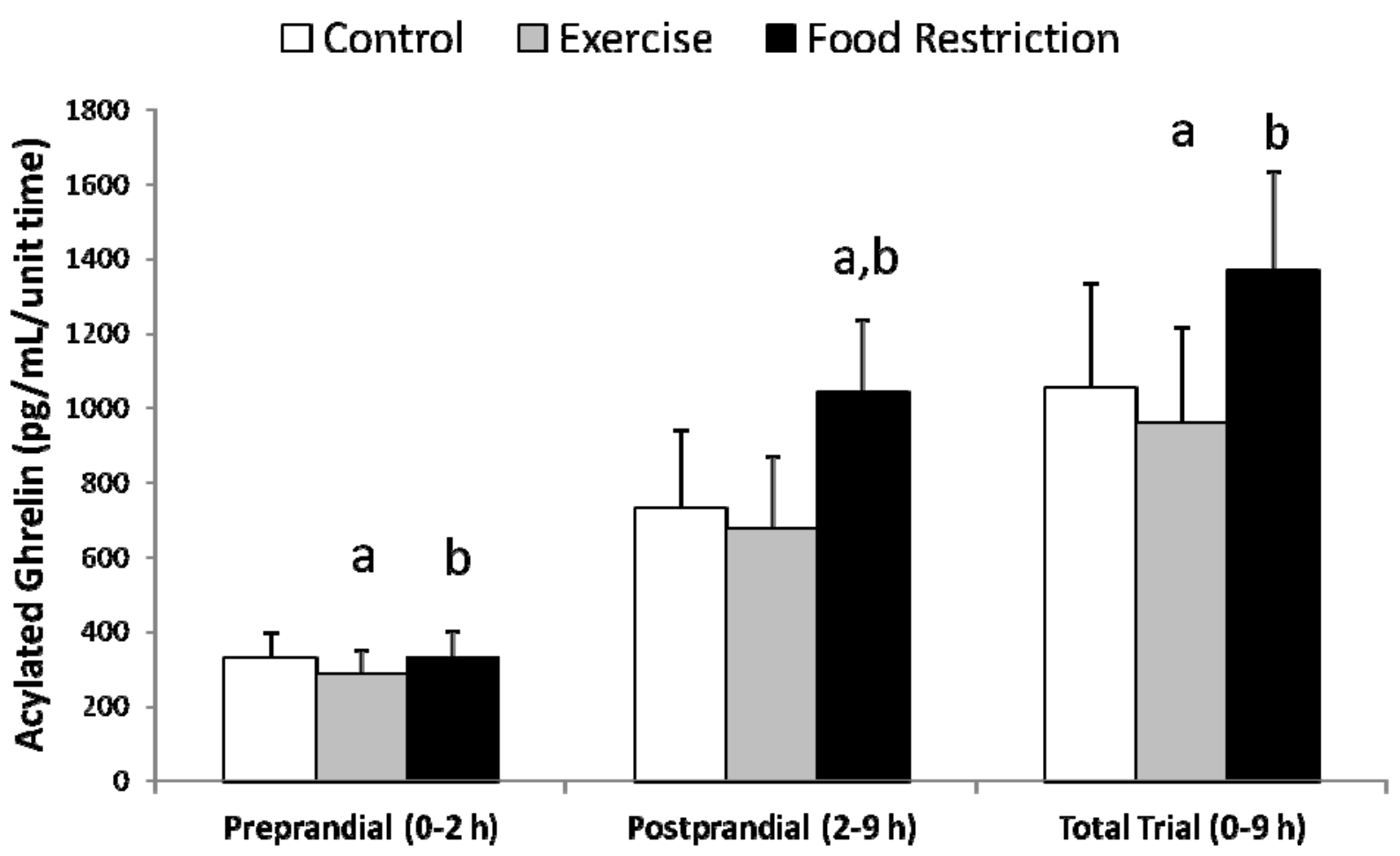

957 
Figure 3

962

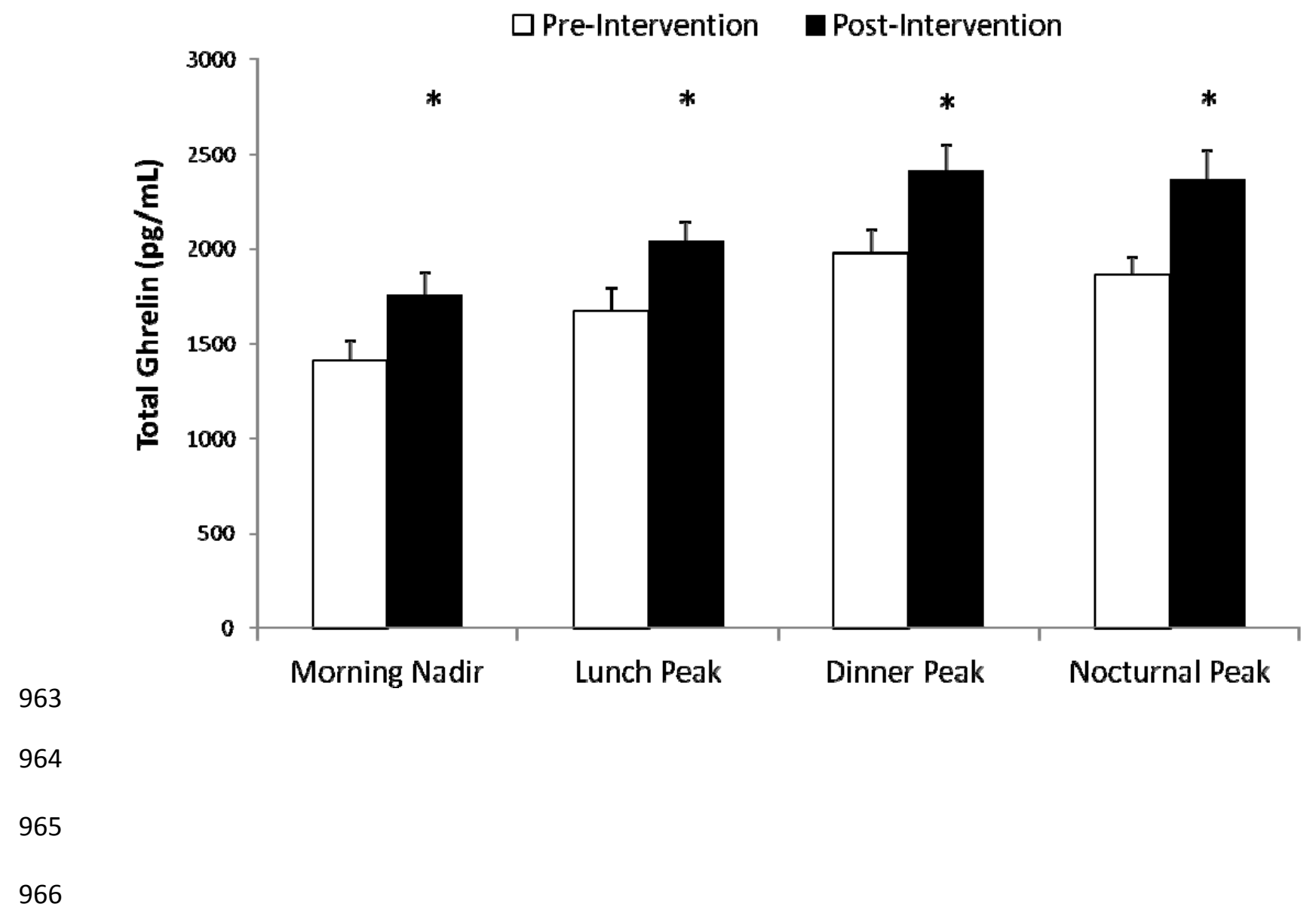

